\title{
Tropical Pacific climate response to obliquity forcing in the Pleistocene
}

\author{
S.-Y. Lee and C. J. Poulsen \\ Department of Geological Sciences, University of Michigan, Ann Arbor, Michigan, USA \\ Received 21 March 2005; revised 7 July 2005; accepted 8 August 2005; published 29 October 2005.
}

[1] Marine proxy records of Pleistocene seawater temperature and productivity in the tropical Pacific Ocean vary over a 41,000-year period that has been attributed to Earth's obliquity cycle. The proxy records are paradoxical both because obliquity has a small effect on low-latitude insolation and because tropical seawater temperature and productivity were anticorrelated with obliquity insolation forcing. In this study, we investigate the response of the tropical Pacific climate to obliquity forcing using a coupled ocean-atmosphere model to reconcile the proxy records with climate theory. Two glacial and two modern simulations were completed with extreme high and low axial tilts of $24.5^{\circ}$ and $22.2^{\circ}$. In response to an increase in axial tilt, tropical sea surface temperatures decrease by as much as $0.8^{\circ} \mathrm{C}$ because of the local reduction in insolation. Subsurface water temperatures in the eastern and central equatorial Pacific increase by nearly $1{ }^{\circ} \mathrm{C}$. Anomalous heating through high-obliquity forcing also generates dynamical responses that weaken mean annual midlatitude westerlies and subtropical trade winds, contributing to a $\sim 20 \%$ reduction in the subtropical gyre circulation. Analyses using a Lagrangian transport model indicate that low-latitude subsurface warming is due to a reduction in heat export from the tropics and the advection and ventilation of anomalously warm South Pacific extratropical waters through the thermocline circulation. The model's response to obliquity is consistent with Pleistocene proxy data that indicate the tropical Walker circulation and thermocline slope were not strongly influenced by changes in axial tilt. The model results also support the hypothesis that Earth's obliquity influences climate through its control on meridional insolation gradients.

Citation: Lee, S.-Y., and C. J. Poulsen (2005), Tropical Pacific climate response to obliquity forcing in the Pleistocene, Paleoceanography, 20, PA4010, doi:10.1029/2005PA001161.

\section{Introduction}

[2] Marine proxy records from the tropical Pacific Ocean preserve strong 41-kyr periodicities in Pleistocene seawater temperature and productivity that are attributed to fluctuations in Earth's obliquity [Clemens et al., 1991; Beaufort et al., 2001; Lea et al., 2000; Liu and Herbert, 2004; de Garidel-Thoron et al., 2005]. These low-latitude records are remarkable because unlike at high latitudes, local insolation forcing due to obliquity oscillations is quite small. Mean annual insolation forcing at the equator differs by $-3 \mathrm{~W} \mathrm{~m}^{-2}$ between times of high (i.e., axial tilt of $24.5^{\circ}$ ) and low (i.e., axial tilt of $22.2^{\circ}$ ) obliquity, representing an annual change of approximately $-0.4 \%$. In comparison, mean annual insolation differs by 15.4 and $6.5 \mathrm{~W} \mathrm{~m}^{-2}$ at $90^{\circ}$ and $65^{\circ}$, respectively, representing increases of 9.3 and $3.0 \%$.

[3] In light of the small influence of obliquity on lowlatitude insolation the 41-kyr periodicities in tropical marine proxy reconstructions are unlikely to arise as a direct climate response to obliquity forcing of local insolation. Moreover, records of Pleistocene tropical seawater temperature are antiphased with local annual insolation; during times of high (low) axial tilt, Pacific seawater temperatures are high (low) [Lea et al., 2000; Liu and Herbert, 2004; de

Copyright 2005 by the American Geophysical Union. 0883-8305/05/2005PA001161
Garidel-Thoron et al., 2005]. What, then, is the source of the 41-kyr periodicities in tropical proxy records? Two possibilities stand out. First, the Pleistocene tropics may have been influenced by direct obliquity forcing of highlatitude insolation [Liu and Herbert, 2004]. In this case, a remote connection, possibly via atmospheric or thermocline circulation, coupled the tropics to the high latitudes. Second, the tropical climate may have been forced by other climate factors, notably atmospheric $\mathrm{CO}_{2}$, that were indirectly influenced by obliquity oscillations. Ice volume changes driven by obliquity variations generated ice proximal changes in sea surface temperature (SST), North Atlantic Deep Water (NADW) formation, and dust that may have caused a strong $\mathrm{CO}_{2}$ feedback [Ruddiman, 2003].

[4] To decide between these possibilities, it is necessary to understand how the tropical climate responded to obliquity forcing in the Pleistocene. Interpretations of tropical marine proxy records provide opposing views; obliquity oscillations either triggered basin-wide dynamical adjustments in the tropics or they did not. The former view is founded on interpretations of marine records of the alkenone unsaturation index $\left(U_{37}^{K^{\prime}}\right)$ and total alkenone abundance from Site 846 in the eastern equatorial Pacific (EEP). Liu and Herbert [2004] report low (high) EEP seawater temperature and high (low) EEP productivity during times of low (high) axial tilt. To explain this record, Liu and Herbert [2004] favor a mechanism that involves enhancement of the 
trade winds and shoaling of the EEP thermocline during low axial tilt, leading to increased upwelling, higher productivity, and lower seawater temperature.

[5] However, other tropical proxy records do not necessarily support obliquity-driven changes in trade wind strength and thermocline slope. Beaufort et al. [2001] report an empirical orthogonal function (EOF) analysis of Pleistocene variations in primary productivity in the Indian and Pacific oceans. The components of the EOF are not consistent with an increase in thermocline tilt, the expected response to enhanced trade winds [Beaufort et al., 2001]. de Garidel-Thoron et al. [2005] demonstrate that over glacial-interglacial cycles, $\mathrm{Mg} / \mathrm{Ca}$-derived seawater temperatures in the western equatorial Pacific covary with the $U_{37}^{K^{\prime}}$ temperatures from Site 846 in the EEP and have similar amplitudes of change. Taken together, these tropical Pacific proxy records indicate a relatively constant east-west SST gradient and imply a stable cross-Pacific thermocline structure (tilt). Many low-latitude marine proxy records from the Pacific Ocean [e.g., Perks and Keeling, 1998; Perks et al., 2002] and the Arabian Sea [e.g., Reichart et al., 1998; Budziak et al., 2000] that might be expected to preserve basin-wide changes in trade wind strength and thermocline depth either lack or have very weak 41-kyr cycles that are secondary to the 23-kyr precessional cycle. Basin-wide dynamical adjustments in the tropics may not be necessary to explain the EEP proxy records. On the basis of SST records derived from census data of radiolarian microfossils, Pisias and Mix [1997] suggest that the 41-kyr cycles in EEP SSTs are linked to the climate response of the Southern Ocean, transmitted through the Peru Current and/or Subantarctic Mode Water.

[6] The purpose of this study is to clarify how the tropical Pacific Ocean responded to obliquity forcing in the Pleistocene and to reconcile, if possible, the apparently contradictory proxy records. Because Pleistocene climates varied between glacial-interglacial states, we have completed two glacial and two nonglacial (modern) experiments under high- and low-obliquity conditions using a coupled oceanatmosphere general circulation model. In section 3 we summarize the model's response to obliquity forcing with emphasis on tropical climate change. In section 4 we compare the model's results with the proxy evidence to substantiate our model's results.

\section{Model and Experimental Design}

[7] Glacial and modern climate experiments were completed using Fast Ocean Atmosphere Model (FOAM), version 1.5 , a fully coupled mixed-resolution ocean and atmosphere general circulation model (GCM). The atmospheric model is a parallelized version of the Community Climate Model, version 2 (CCM2), with the radiative and hydrological physics upgraded to the equivalent of version 3.2 (CCM3) [Kiehl et al., 1996]. The atmospheric component of FOAM was run at spectral resolution R15 $\left(4.5^{\circ} \times\right.$ $7.5^{\circ}$ ) with 18 vertical levels. The ocean component of FOAM (OM3) is a $z$ coordinate ocean general circulation model with a $128 \times 128$ point Mercator grid $\left(1.4^{\circ} \times 2.8^{\circ}\right)$ and 24 vertical levels.
[8] FOAM has been widely used to study climate change through geologic time [e.g., Liu et al., 2000b; Poulsen et al., 2001; Harrison et al., 2003; Poulsen et al., 2003; Pierrehumbert, 2004]. FOAM's simulation of modern climate shows reasonable agreement with present-day observations. In addition to the mean climate state, FOAM successfully simulates many aspects of modern interannual and interdecadal variability, including the El Niño-Southern Oscillation (ENSO) [Jacob, 1997; Liu et al., 2000a, 2002]. FOAM's most important shortcoming is an underestimation of NADW production in the modern climate, a problem common to coupled ocean-atmosphere models. However, we do not consider this to be an important limitation for two reasons: (1) We restrict our analyses to the upper ocean circulation, and (2) a persistent bias in the thermohaline circulation will be prevalent in both sensitivity experiments and will be effectively filtered out by comparing (differencing) the experiments.

[9] In a recent comparison of the simulation of global upper ocean circulation between FOAM and the National Center for Atmospheric Research Community Climate System Model (CCSM), Liu et al. [2003] showed that in many regions the two models respond consistently to Holocene orbital forcing. In fact, FOAM's sensitivity to a doubling of atmospheric $p \mathrm{CO}_{2}$ is similar to that of the CCSM (R. Jacob, personal communication, 2004), approximately $2^{\circ} \mathrm{C}$ or $0.5^{\circ} \mathrm{C} \mathrm{W}^{-1} \mathrm{~m}^{-2}$ [Merilees, 2003].

[10] We initially completed two glacial sensitivity experiments: high-obliquity (HOBL) and low-obliquity (LOBL) cases with axial tilts of $24.5^{\circ}$ and $22.2^{\circ}$, respectively. These experiments represent continuation runs from a preexisting Last Glacial Maximum (LGM) experiment and were each integrated for an additional 150 years to bring the upper ocean to steady state. LGM boundary conditions include Eurasian and North American ice sheets, reduced sea level, LGM continental topography, and vegetation distribution [Peltier, 1994]. Orbital settings were set to those for $18 \mathrm{ka}$ on the basis of Berger [1978]. LGM greenhouse gas levels were inferred from Vostok ice cores; $\mathrm{CO}_{2}, \mathrm{CH}_{4}$, and $\mathrm{N}_{2} \mathrm{O}$ were prescribed as $200 \mathrm{ppmv}, 400 \mathrm{ppbv}$, and $275 \mathrm{ppbv}$, respectively [Petit et al., 1999]. The FOAM LGM simulation has a global mean annual temperature of about $8^{\circ} \mathrm{C}$. Tropical Pacific SSTs in the LGM simulation are approximately $4-5^{\circ} \mathrm{C}$ below modern values, comparing favorably with colder SST paleoestimates [Beck et al., 1997; Mix et al., 1999; Martinez et al., 2003].

[11] We chose to use glacial experiments in this study to maximize the tropical response to obliquity forcing. On the basis of thermocline theory a cold climate with shallower equatorial thermocline should be most sensitive to obliquity forcing [Philander and Federov, 2003]. After analyzing the glacial obliquity experiments, two additional obliquity sensitivity experiments were conducted using present-day boundary conditions (see section 3.3). These experiments represent 150 -year continuation runs of a present-day simulation. All model results described in section 3 and throughout the paper represent averages of the last 20 years of model integrations.

[12] To analyze the GCM results, we developed a Lagrangian transport model to track water parcel trajectories 


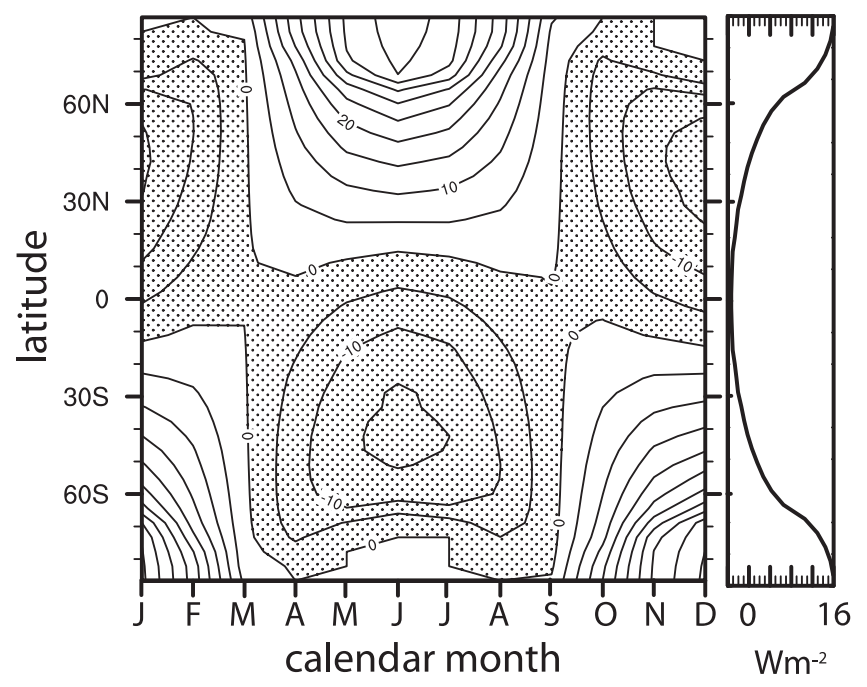

Figure 1. (left) Seasonal and (right) mean annual solar insolation difference between high obliquity (HOBL) and low obliquity (LOBL). Under high obliquity, seasonal and annual meridional insolation gradients are reduced. The contour interval is $10 \mathrm{~W} \mathrm{~m}^{-2}$.

within the interior of the ocean, a standard technique for analyzing water parcel pathways [e.g., Harper, 2000]. The transport model interpolates the three-dimensional velocity field to the position of a water particle and then uses a second-order finite difference technique to predict the future position of the water particle. We linearly interpolated between monthly average velocities to calculate the timevarying velocity field at each 30 -min time step. The Lagrangian transport model only calculates transport through advection and therefore should be considered an approximation of the GCM-simulated flow.

\section{Results}

\subsection{Seawater Temperature}

[13] Figure 1 displays the seasonal and mean annual solar insolation difference between the HOBL and LOBL experiments. A higher axial tilt reduces the mean annual and seasonal meridional insolation gradient [Berger, 1978]. Figures $2 \mathrm{~b}$ and $2 \mathrm{c}$ illustrate the mean annual seawater temperature difference at the surface (10-m depth) and subsurface (average of 30- to 100-m depths) between the HOBL and LOBL experiments. At the sea surface the temperature difference is largely zonal and consistent with the local mean annual insolation change due to an increase in Earth's axial tilt. Poleward of approximately $30^{\circ}$, annual SSTs increase by more than $1^{\circ} \mathrm{C}$. At low latitudes, annual SSTs cool by up to $0.6^{\circ} \mathrm{C}$ (Figure 2b). Seasonal SST differences between the HOBL and LOBL experiments are also mainly associated with local insolation differences; for example, midlatitude SST differences are largest during the summer when the insolation difference is greatest (Figure 3). However, both mean annual and seasonal SST differences demonstrate variations from the zonal SST pattern that are linked to dynamical changes forced by seasonal variations in insolation (see section 3.2).
[14] Subsurface $(30-100 \mathrm{~m})$ seawater temperatures respond very differently to an increase in obliquity. Although the local insolation is reduced, subsurface seawater temperatures are higher in a tongue that extends across the equatorial Pacific. EEP subsurface temperatures increase by more than $0.6^{\circ} \mathrm{C}$ in the HOBL experiment. In both hemispheres, subsurface waters in the subtropical Pacific
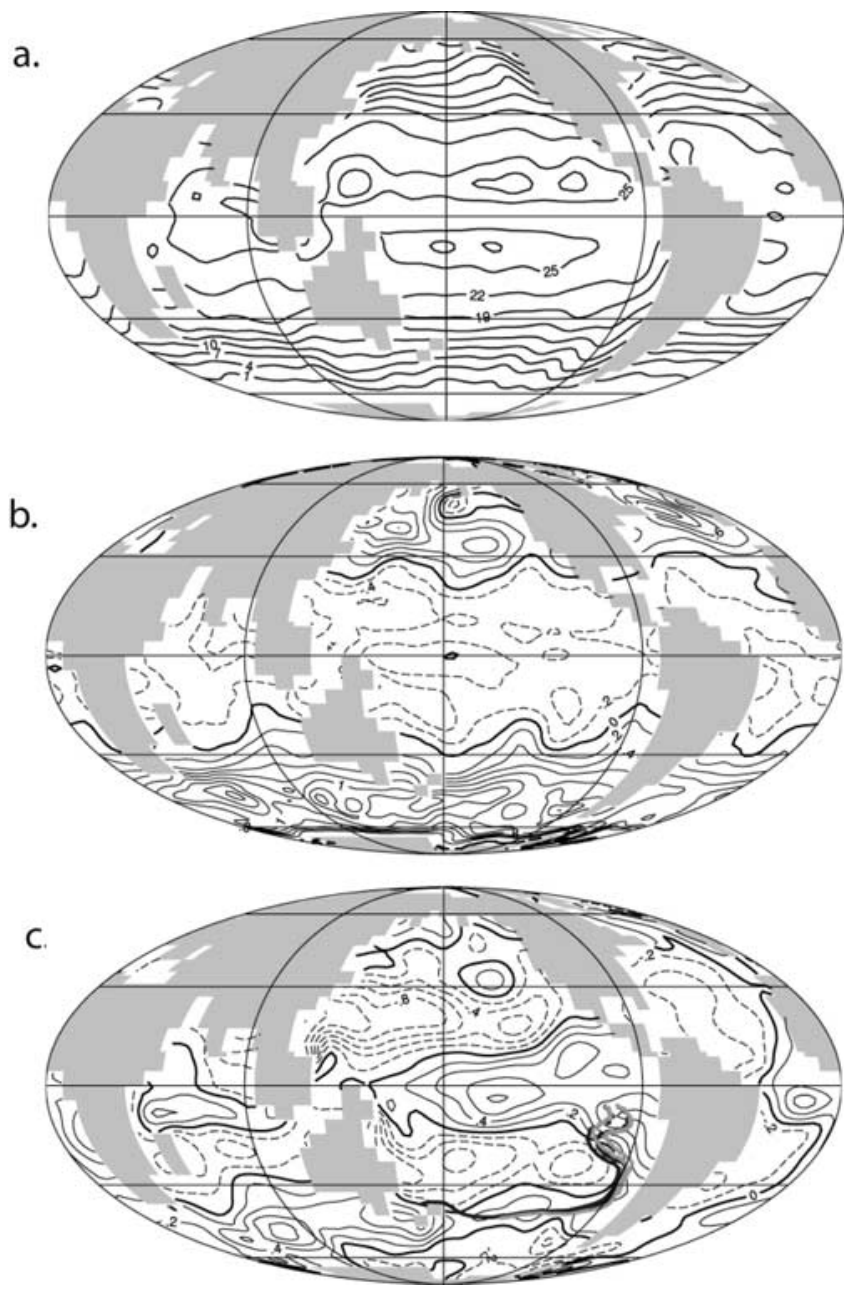

Figure 2. (a) Simulated mean annual sea surface temperature in the glacial HOBL experiment. Glacial tropical sea surface temperatures (SSTs) are approximately $4^{\circ} \mathrm{C}$ cooler than modern SSTs. (b) Surface and (c) subsurface (30$100 \mathrm{~m}$ ) temperature differences between the HOBL and LOBL experiments. In response to an increase in obliquity, tropical SSTs cool by up to $0.6^{\circ} \mathrm{C}$, but tropical subsurface waters warm by up to $0.8^{\circ} \mathrm{C}$. Southern Hemisphere water particle paths calculated using a Lagrangian transport model are shown in Figure 2c. The thick black (gray) line represents the particle trajectory in the HOBL (LOBL) experiment. The length of the trajectory indicates the speed of the flow. Thus the trajectories indicate that flow through the subtropical gyre is faster in the LOBL experiment than the HOBL experiment. The contour interval is $3^{\circ} \mathrm{C}$ in Figure $2 \mathrm{a}$ and $0.2^{\circ} \mathrm{C}$ in Figures $2 \mathrm{~b}$ and $2 \mathrm{c}$; the dashed line in Figures $2 \mathrm{~b}$ and $2 \mathrm{c}$ represents a temperature decrease. 

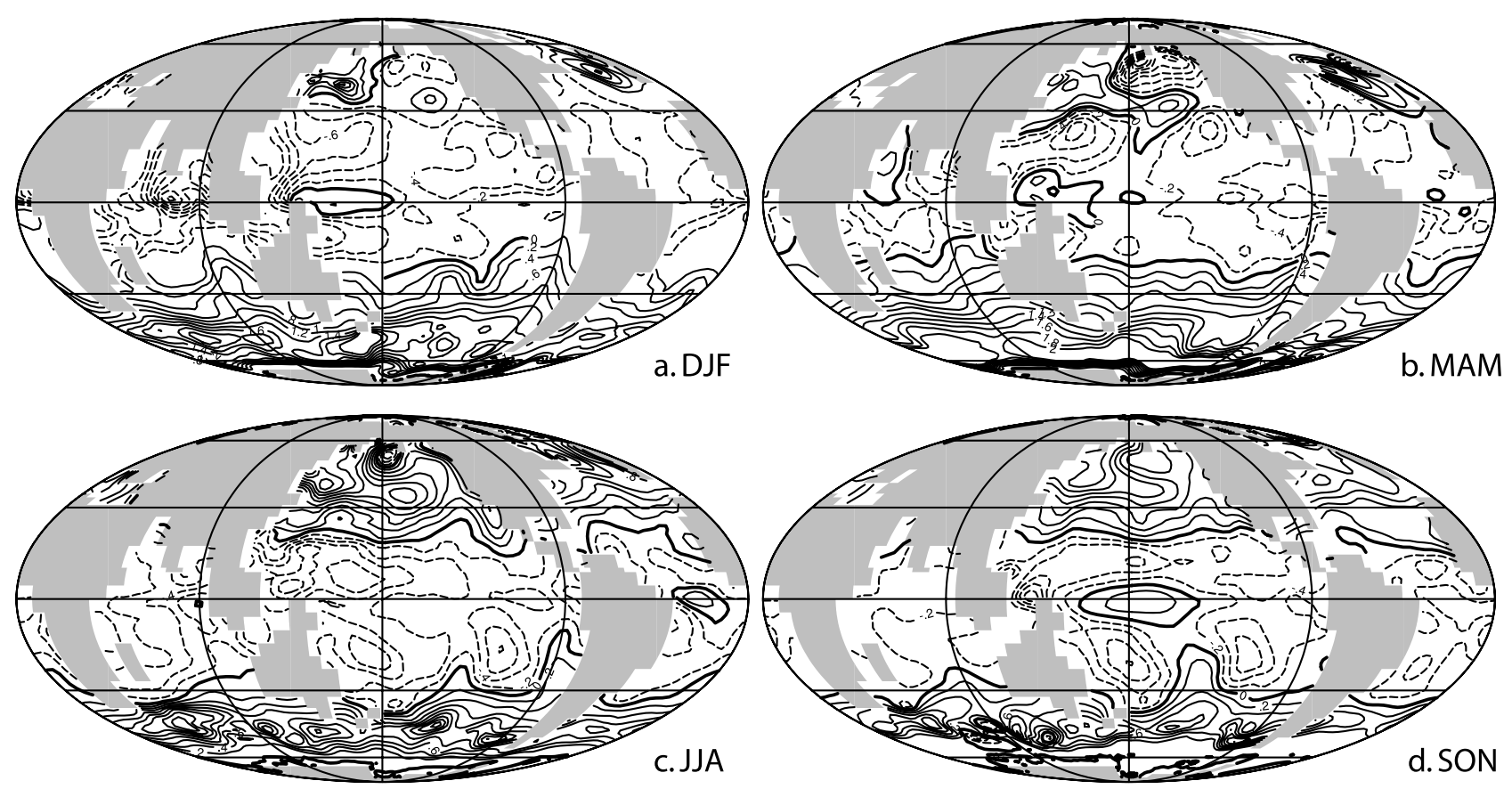

Figure 3. Simulated seasonal sea surface temperature $\left({ }^{\circ} \mathrm{C}\right)$ difference between HOBL and LOBL experiments during (a) December, January, and February (DJF), (b) March, April, and May (MAM), (c) June, July, and August (JJA), and (d) September, October, and November (SON). Seasonal differences are linked to seasonal insolation differences or dynamical responses to seasonal insolation differences (see text). The contour interval is $0.2^{\circ} \mathrm{C}$; lower temperatures are indicated by dashed contour.

are up to $1.2^{\circ} \mathrm{C}$ cooler (Figure $2 \mathrm{c}$ ). Subsurface seawater temperatures show only minor seasonal variation. Crosssectional maps of seawater temperature in the tropical Pacific (averaged from $4^{\circ} \mathrm{N}$ to $4^{\circ} \mathrm{S}$ ) indicate a slight depression of the thermocline $(\sim 20 \mathrm{~m})$ in the central and eastern Pacific (not shown).

\subsection{Dynamical Response to Obliquity Forcing}

[15] The dynamical response to obliquity forcing is complicated by the large seasonal insolation anomalies. The seasonal adjustments in heating, sea level pressure, and winds to this insolation forcing are described in this section. In the mean annual the dynamical response is conceptually much simpler. The response to an increase in axial tilt is a decrease in the midlatitude westerlies and tropical easterlies associated with a reduction in meridional insolation and surface pressure gradients (Figure 4d).

[16] As shown in Figure 1, changes in obliquity significantly alter the seasonal meridional insolation distribution, leading to anomalous heating at the surface, which spawns dynamical changes that influence the mean circulation of the atmosphere and ocean. During the late fall and winter, for example, the HOBL experiment is forced by anomalously low insolation in the midlatitudes. The anomalously low insolation and surface cooling in the midlatitudes (centered at $45^{\circ}$ ) lead to a positive surface pressure anomaly and a weakening of the midlatitude low pressure (e.g., the Aleutian Low in the North Pacific). The surface wind response is an anticyclonic anomaly that includes a weakening of the midlatitude westerlies and a slight intensifica- tion of the northernmost trade winds in the northwestern Pacific (Figure 4a).

[17] Conversely, in the summer hemisphere, anomalous high insolation and surface heating in the extratropics lead to a weakening of the subtropical high and the trade winds (Figure 4c). FOAM also predicts a slight intensification of the EEP trade winds during boreal spring (Figure 4b). As pointed out by Clement et al. [2000], rapid seasonal heating along the equator preferentially warms the western Pacific warm pool, intensifying the west-east SST gradient and strengthening trade winds. However, because summer insolation dominates the mean annual insolation anomaly, the mean annual signal is one of weaker tropical easterlies (Figure 4e). It should be noted that differences in trade wind strength primarily occur away from the equator; there is little change in the near-equatorial trade winds because there is little change in the low-latitude insolation gradients.

[18] The obliquity-driven modifications to surface winds affect the wind-driven circulation in the Pacific Ocean. Pronounced changes include weakening of the Northern Equatorial Current (NEC) and the subtropical gyre and enhanced flow through the Northern Equatorial Countercurrent (NECC) and Southern Equatorial Current (SEC). These changes are displayed as a reversal of flows in the HOBL-LOBL difference plot (Figure 5). We estimate a 14\% reduction in the transport volume of the Kuroshio Current at $25^{\circ} \mathrm{N}$. Analysis with our Lagrangian transport model presents a consistent picture; the travel time of a water parcel through the Peru Current is $20 \%$ greater in the HOBL experiment than in the LOBL experiment. The weakening 


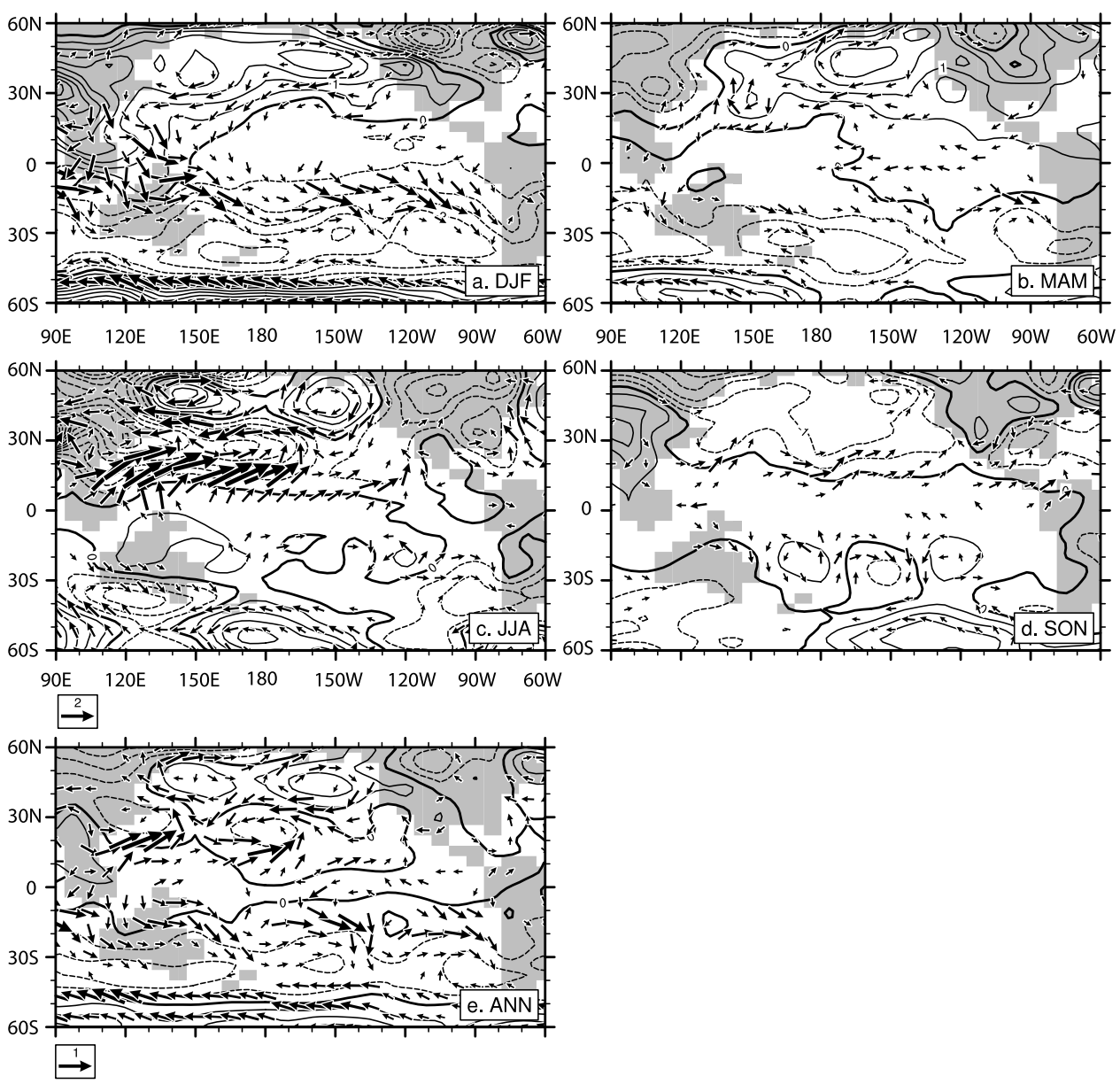

Figure 4. Seasonal and mean annual differences in near-surface wind (vectors) and surface level pressure (SLP) (contours) between HOBL and LOBL. Seasonal differences in insolation forcing generate SLP and near-surface wind anomalies. For example, in MAM, subtropical heating (cooling) intensifies (reduces) the subtropical high, leading to stronger (weaker) trades in the Northern (Southern) Hemisphere. Only wind vector differences greater than $(a-d) 0.5 \mathrm{~m} \mathrm{~s}^{-1}$ and (e) $0.25 \mathrm{~m} \mathrm{~s}^{-1}$ are displayed. The SLP contour interval is 0.5 mbar; the dashed contours represent a decrease in SLP. ANN is mean annual.

of the subtropical gyres in the HOBL experiment can be linked to the weakening of the trades and the midlatitude westerlies. The intensifications of the NECC and SEC are likely responses to changes in zonal wind stresses according to Sverdrup theory. In the North Pacific, for example, mean annual zonal average trades centered on $30^{\circ}$ latitude intensify while those centered on $15^{\circ}$ latitude weaken (Figure 6a). The anomalous wind stress caused by the change in trades promotes Ekman transport that sets up anomalous convergence at $\sim 10^{\circ} \mathrm{N}$ and divergence at $\sim 20^{\circ} \mathrm{N}$. As a result of changes in sea level height, surface pressure gradients are enhanced between $10^{\circ} \mathrm{N}$ and $20^{\circ} \mathrm{N}$ and between $10^{\circ} \mathrm{N}$ and $0^{\circ}$, intensifying both the eastward flowing NECC and the westward flowing SEC (Figure 6b).

\subsection{Cause of Tropical Pacific Subsurface Warming}

[19] Several mechanisms could potentially explain the subsurface warming in the tropical Pacific under highobliquity forcing, including (1) reduced EEP upwelling through a reduction in low-latitude trade wind strength, (2) a change in the source of ventilated waters in the EEP caused by a change in subsurface circulation, (3) warming of source waters through high-latitude obliquity forcing without any subsurface circulation change, and/or (4) a decrease in tropical heat transport and thermocline ventilation due to a reduction in the subtropical gyre. Our model results do not show a significant trade wind-thermocline feedback to obliquity forcing. The absence of this feedback can be readily seen in the SST difference between experiments, which is largely zonal at low latitude (Figure 2b). Moreover, the subsurface warming in the equatorial Pacific under high-obliquity conditions persists throughout the year with little seasonal variation (Figure 2c). Most significantly, the mean annual trade wind strength near the equator shows little change between the HOBL and LOBL experiments (Figure 4e). As expected from the insignificant surface wind differences, low-latitude Ekman pumping is nearly unchanged between experiments (not shown). 


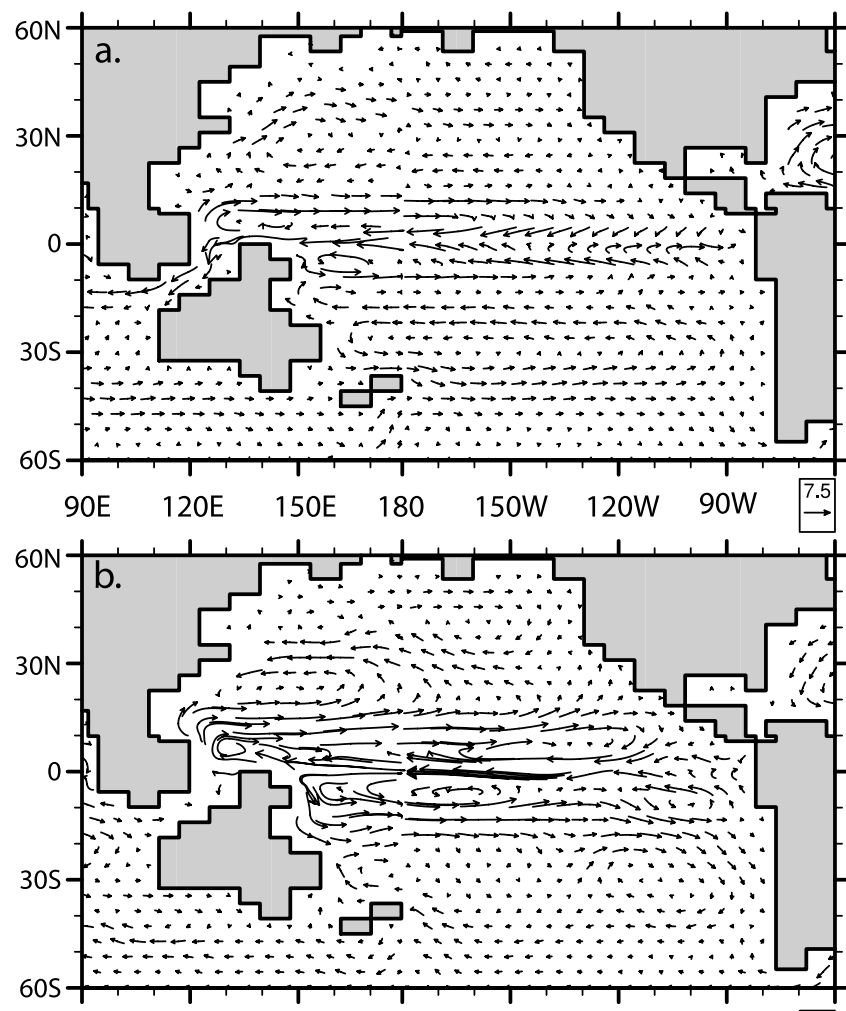

Figure 5. (a) Mean annual subsurface (30-100 m) flow in the HOBL experiment. (b) Difference in the subsurface flow between the HOBL and LOBL experiments. As indicated by their reversal in the difference plot, the subtropical gyres slow, while the Northern Equatorial Countercurrent (NECC) and Southern Equatorial Current (SEC) increase in speed. Note the difference in the reference vectors between plots. Reference vectors are in $\mathrm{cm} \mathrm{s}^{-1}$.

[20] The model results indicate that the tropical subsurface warming is largely due to subduction and advection of anomalously warm southern midlatitude waters through the thermocline circulation. Figure 7 shows the seawater temperature difference between the HOBL and LOBL experiments through a meridional cross section in the eastern South Pacific Ocean. A warm anomaly can be traced from the surface of the midlatitude South Pacific to the thermocline of the EEP (Figure 7). To further investigate the source of the waters ventilated in the EEP, we used a Lagrangian transport model driven by the monthly mean ocean velocities predicted by FOAM. Figure $2 \mathrm{c}$ illustrates the paths of water parcels over a 20 -year integration for the HOBL and LOBL experiments. In both experiments, EEP waters originate from very nearly the same location in the South Pacific and follow almost identical subsurface paths to the EEP. However, the source water temperature in the HOBL experiment is $0.6^{\circ}$ warmer at the surface than in the LOBL experiment (Figure 2b).

[21] Two physical factors contribute to extratropical warming in the HOBL experiment: an increase in insolation and a decrease in the sea ice distribution. At $45^{\circ} \mathrm{S}$, annual insolation forcing is $0.55 \mathrm{~W} \mathrm{~m}^{-2}$ with a $2^{\circ}$ increase in axial tilt. Figure 8 shows the sea ice distribution in two experiments. The sea ice distribution is very sensitive to obliquity forcing; the sea ice distribution in the LOBL experiment is $2^{\circ}-10^{\circ}$ north of that in the HOBL experiment. In the LOBL experiment, cold air advected from the sea ice surface to the ocean leads to a sensible heat loss of $1-6 \mathrm{~W} \mathrm{~m}^{-2}$ at $45^{\circ} \mathrm{S}$ and sea surface cooling. In the absence of this sensible heat loss and insolation heating the HOBL seawater temperature is higher in midlatitudes.

[22] The sensitivity of the EEP subsurface temperatures to South Pacific sea ice distribution suggests that the tropical response to obliquity forcing may be very different in nonglacial climates. To test this idea, we ran two modernday climate simulations with high-obliquity $\left(24.5^{\circ}\right)$ and low-obliquity $\left(22.5^{\circ}\right)$ forcing, respectively. In both modern experiments the sea ice line was well poleward of $70^{\circ}$. As in the glacial experiments, the main tropical response to obliquity forcing was a $\sim 0.6^{\circ} \mathrm{C}$ decrease in SSTs and an increase in subsurface temperatures. However, with the reduction in sea ice the magnitude and extent of the tropical subsurface warming was substantially reduced.

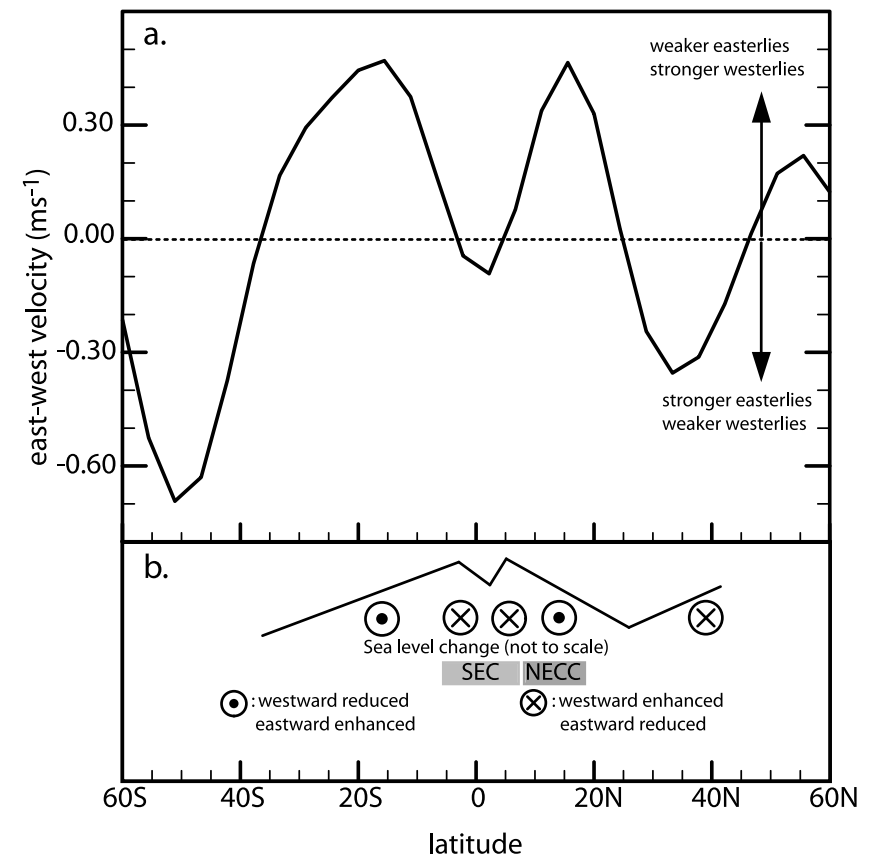

Figure 6. (a) Difference (HOBL-LOBL) in zonal average mean annual surface wind $\left(\mathrm{m} \mathrm{s}^{-1}\right)$ over the Pacific $\left(120^{\circ} \mathrm{E}-\right.$ $90^{\circ} \mathrm{W}$ ). As indicated by the positive (eastward) wind difference, in the Northern Hemisphere the off-equatorial trade winds weaken around $15^{\circ}$ and intensify near $30^{\circ}$ in the HOBL experiment. (b) Schematic displaying the effect of the change in zonal wind stress on the equatorial currents, according to Sverdrup theory. The solid line represents the change in relative sea level height due to the changes in zonal wind with latitude. The symbols represent the relative change in current direction. Note that the SEC and the NECC both strengthen; the Northern Equatorial Current weakens. 


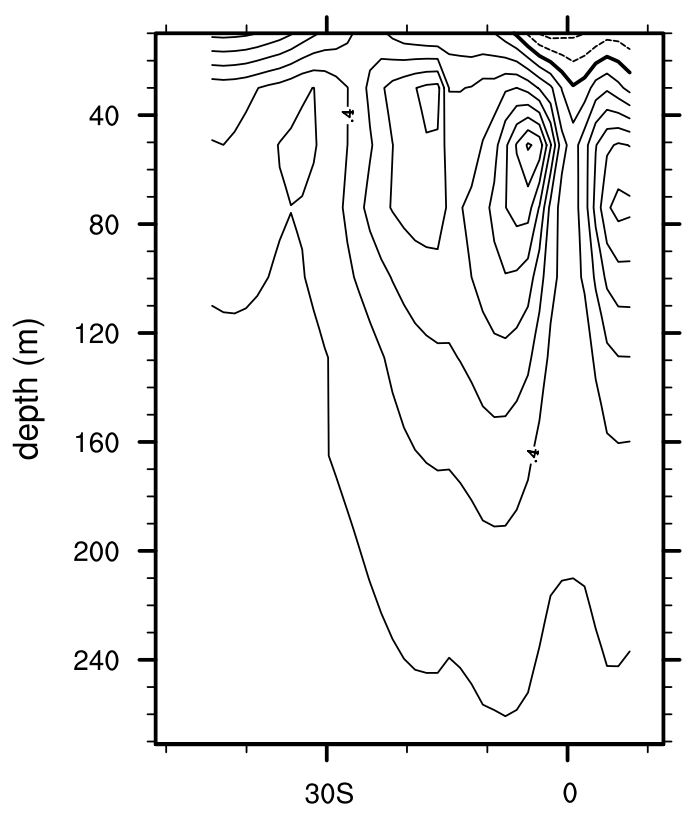

Figure 7. Cross section of seawater temperature difference (HOBL-LOBL) in the eastern South Pacific $\left(77.4^{\circ} \mathrm{W}-\right.$ $\left.91.4^{\circ} \mathrm{W}\right)$. The contour interval is $0.2^{\circ} \mathrm{C}$.

[23] In addition to the ventilation of warmer waters, the slowing of the boundary currents may also contribute to the subsurface differences between the HOBL and LOBL experiments. The reduction in the subtropical gyres diminishes the heat transport from the equator, contributing to subsurface warming in the eastern and central tropical Pacific and subsurface cooling in subtropical temperatures in the HOBL experiment (Figure 2c). The reduction in wind-driven ocean circulation under high-obliquity forcing may be important to understanding oceanic paleoproductivity records from the Pacific Ocean. Our model results provide a mechanism for generating a 41-kyr productivity signal. In the modern ocean, Subantarctic Mode Water is the main channel of nutrients from the Southern Ocean to the equatorial Pacific and the main source of nutrients for the thermocline [Toggweiler et al., 1991; Sarmiento et al., 2003]. We suggest that a weakening (strengthening) of the subtropical gyres would effectively reduce (enhance) the transport of nutrients in the thermocline during periods of high (low) obliquity, thereby reducing (enhancing) biological productivity.

\section{Discussion}

\subsection{Low-Latitude Response to Obliquity Forcing}

[24] Several proxy records from the tropical Pacific preserve a 41-kyr signal related to obliquity forcing. Our model results provide two mechanisms for amplifying the low-latitude obliquity forcing: (1) modifying the strength of the wind-driven ocean circulation and the advection of nutrients and (2) transmitting midlatitude thermal anomalies to low latitudes through the thermocline circulation.

[25] The thermocline response in our model is consistent with our understanding of the modern thermocline circulation. In the Pacific, tropical thermocline waters are sourced by the subduction of late winter surface waters in the midlatitudes [Stommel, 1979; Toggweiler et al., 1991]. Subducted waters reach the tropical thermocline through the eastern boundary currents and interior circulation [Harper, 2000]. According to theories for the thermocline, tropical thermocline depth is dependant on the wind stress and the density gradient across the thermocline, which is determined by the temperature difference $(\Delta T)$ between the surface and the deep ocean [Bocaletti et al., 2004]. In our experiments an increase in axial tilt reduces $\Delta T$ through the subduction and advection of anomalously warm waters into the EEP but has little effect on wind stress, leading to deepening of the thermocline as predicted by theory.

[26] A number of recent modeling studies have reported the substantial influence of the precessional cycle on the tropical Pacific climate [e.g., Clement et al., 2000; Liu et al., $2000 \mathrm{~b}$. Our results are generally consistent with these. For example, the thermocline response to Holocene orbital forcing (predominantly precessional forcing) was determined mainly by surface water subduction driven by insolation forcing in the late winter [Liu et al., 2003]. In contrast to our results, the thermocline response to Holocene orbital forcing propagated to the sea surface, leading to cooler SSTs in the EEP and more La Niña-like conditions [Liu et al., 2003]. The difference in the surface response is linked to the difference in the nature of the orbital forcing. Because obliquity forcing has little effect on low-latitude insolation, it does little to influence trade wind strength near the equator. In contrast, by intensifying low-latitude seasonal insolation differences in the Northern Hemisphere, precessional forcing strengthens the trades by intensifying the summer monsoons from Asia and North America [Liu et al., 2000b] and increasing the tropical east-west thermal
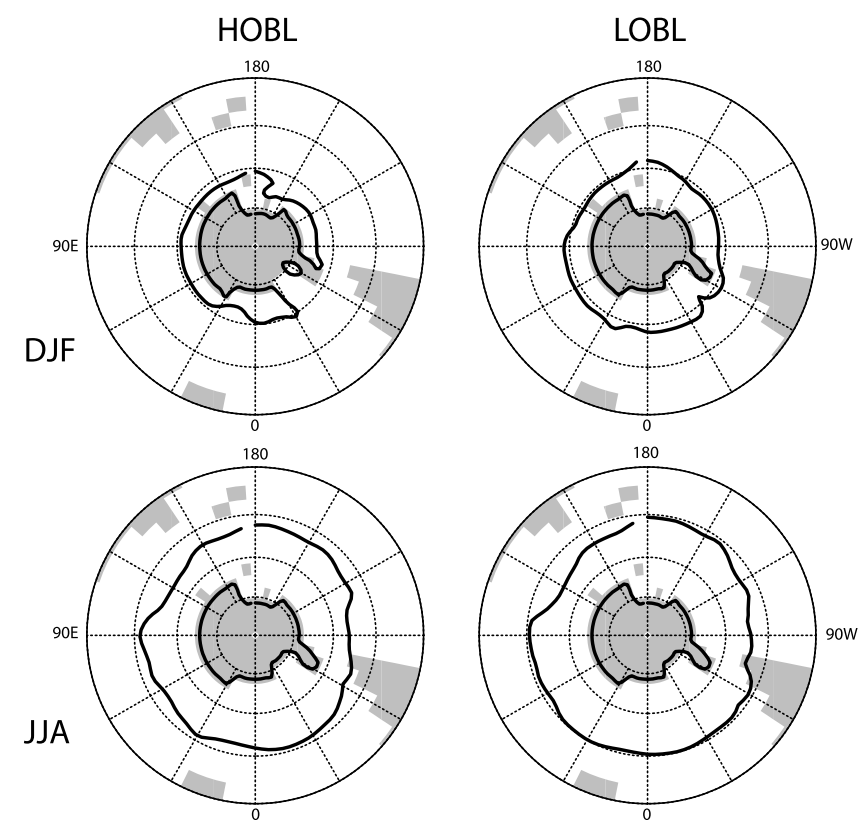

Figure 8. Seasonal (DJF and JJA) sea ice distributions in the Southern Hemisphere for the (left) HOBL and (right) LOBL experiments. Note that the sea ice distribution is farthest equatorward in the LOBL experiments. The polar projection map begins at $30^{\circ} \mathrm{S}$; the continents are shaded. 
gradient through rapid summer insolation warming of the western Pacific warm pool [Clement et al., 2000].

\subsection{Comparison With Tropical Marine Proxy Records}

[27] We suggest that FOAM's response to a change in obliquity is consistent with Pleistocene marine proxy records from the tropical Pacific. As indicated by the lack of an eastwest productivity gradient across the tropical Pacific and Indian Oceans [Beaufort et al., 2001] and a stable $\Delta$ SST across the tropical Pacific during glacial-interglacial oscillations [de Garidel-Thoron et al., 2005], marine proxy records indicate only minor changes in tropical thermocline structure in response to the obliquity cycle. FOAM also predicts only minor changes in the thermocline that do not strongly affect surface properties. Neither the proxy records nor the model support the idea that fluctuations in the axial tilt drove large-scale dynamical changes involving the Walker circulation and thermocline tilt. Rather, the FOAM results support the conclusions of Pisias and Mix [1997] that changes in tropical subsurface temperature were linked to the Southern Ocean climate response.

[28] The tropical marine seawater proxies consistently demonstrate an antiphased relationship with obliquity forcing of local insolation [Lea et al., 2000; Liu and Herbert, 2004; de Garidel-Thoron et al., 2005]. During times of high (low) axial tilt, seawater temperatures are relatively high (low). FOAM's response is consistent with the seawater temperature proxies if they are recording subsurface $(\sim 30 \mathrm{~m}$ or below) temperatures, rather than surface temperatures, as often stated in the literature. The secretion of calcite tests by planktonic foraminifera and the growth of haptophyte algae that biosynthesize long-chained alkenones have been observed to occur over a range of depths [Be, 1977; Okada and Honjo, 1973; Okada and McIntyre, 1979; Conte et al., 1994; Ternois et al., 1997]. In general, the magnitude of FOAM's seawater temperature response is consistent with that derived from radiolarian microfossils [Pisias and Mix, 1997] but is less than that indicated by either $\mathrm{Mg} / \mathrm{Ca}$ or $U_{37}^{K^{\prime}}$ paleothermometry [Lea et al., 2000; Liu and Herbert, 2004; de Garidel-Thoron et al., 2005]. If FOAM's obliquity response is too weak, there may be several possible reasons. First, our experiments do not include variations in atmospheric $\mathrm{CO}_{2}$ or global ice volume. Lea [2004] reports a strong correlation at the 41-kyr period between Cocos Ridge SST and atmospheric $\mathrm{CO}_{2}$ from the Vostok ice core. We expect that including $\mathrm{CO}_{2}$ variations in our experiments would have directly amplified the obliquity signal by modifying tropical radiative forcing and indirectly enhanced the obliquity signal by influencing the Southern Ocean sea ice extent and the temperature of subducting midlatitude waters. Second, like most medium-resolution ocean GCMs, FOAM is more diffusive than the real ocean. In a less diffusive model it is possible that the tropical thermocline response to extratropical insolation anomalies may be stronger.

\subsection{Obliquity Forcing and Ice Ages}

[29] Since Milankovitch [1941] proposed the astronomical theory for ice ages, obliquity has been implicated in the growth and decay of continental ice sheets. Milankovitch [1941] proposed that through its control on high-latitude summer insolation, obliquity determined the annual mass balance of an ice sheet. It is now well known that Milankovitch theory falls short on several accounts including its inability to explain (1) the transition from a world dominated by $41-\mathrm{kyr}$ variability at high latitudes to one dominated by $100-\mathrm{kyr}$ variability in the mid-Pleistocene and (2) the fact that precession, rather than obliquity, dominates the summer insolation at high latitudes [Raymo and Nisancioglu, 2003].

[30] New hypotheses that attempt to avoid the problems of the Milankovitch theory have been proposed to explain the link between obliquity and ice ages. To explain the 41kyr period of ice ages before the mid-Pleistocene transition, Raymo and Nisancioglu [2003] suggest that obliquity primarily controlled climate change through its influence on insolation gradients rather than high-latitude summer insolation. In turn, insolation gradients governed the atmospheric fluxes of heat, moisture, and latent energy that controlled ice sheet growth and decay [Young and Bradley, 1984; Raymo and Nisancioglu, 2003]. According to the gradient hypothesis, as obliquity decreased, the insolation gradient increased, driving greater poleward transport of moisture and promoting polar ice sheet growth.

[31] An alternative hypothesis, here deemed the tropical thermocline hypothesis, proposes that prior to the midPleistocene transition, obliquity forcing was amplified by positive feedbacks in the tropics [Philander and Federov, 2003; Ravelo et al., 2004]. The tropical thermocline hypothesis predicts that obliquity influences tropical thermocline waters through its control on mean annual midlatitude insolation where thermocline waters are subducted. In turn, the thermocline temperature governs the SST in regions of equatorial upwelling, leading to changes in the Walker and Hadley circulations that ultimately influence high-latitude climate through teleconnections, much in the same way that ENSO affects global climate [Cane, 1998]. In either hypothesis, ice sheet growth may be amplified by ice proximal changes in SST, NADW, and dust that stimulate a positive $\mathrm{CO}_{2}$ feedback [Ruddiman, 2003].

[32] Our model results provide insights into the role of obliquity forcing on global climate change. Most importantly, our model results predict a weak thermocline response to obliquity forcing, which does not appear at the sea surface. Zonal thermal gradients and trade wind strength vary little within the tropics in response to a change in obliquity. On the other hand, in response to low obliquity the meridional surface air temperature (SAT) gradient increases, intensifying the jet stream, midlatitude westerlies, and subtropical ocean gyres. In both glacial and modern simulations, high-latitude regions are colder and highlatitude snowfall rates and accumulation are greater over much of the Northern Hemisphere under low-obliquity forcing. Jackson and Broccoli [2003] also report increased storminess and snowfall and decreased high-latitude SAT during times of low-meridional SAT gradient. They attribute the increase in Northern Hemisphere storminess to the accumulation of potential energy to the south of the zonal wind anomaly and the tendency for an increase in vertical 
shear to promote faster growth of storms [Jackson and Broccoli, 2003]. Without a dynamic ice sheet model we cannot say whether the reduction in meridional insolation gradient and enhanced snowfall might grow an ice sheet in a more favorable (i.e., preindustrial) mean climate, but our results indicate that insolation gradient-driven moisture fluxes may amplify obliquity forcing. Using a simple coupled atmosphere-ice process model, Nisancioglu [2004] reports that cooler high-latitude temperatures and enhanced moisture transport during times of low obliquity enhance ice sheet expansion.

\section{Summary}

[33] The response of the tropical Pacific climate to obliquity forcing is estimated using a coupled ocean-atmosphere model and compared with Pleistocene marine proxy records from sediment cores recovered from the tropical Pacific. Two glacial simulations with high and low axial tilt were developed and analyzed. In response to an increase in axial tilt the model predicts tropical sea surface cooling associated with the decrease in local insolation. Extratropical surface waters warm because of the increase in local insolation and a decrease in sensible heat loss with a reduction in sea ice.
Anomalous heating through high-obliquity forcing also generates dynamical responses that weaken mean annual midlatitude westerlies and subtropical trade winds, contributing to a $\sim 20 \%$ reduction in the subtropical gyre circulation. Advection and ventilation of anomalously warm extratropical waters and a reduction in heat export from the tropics cause subsurface warming and a slight deepening of the tropical thermocline in the central and eastern equatorial Pacific. Importantly, the subsurface warming in the tropical Pacific does not penetrate the sea surface, and the equatorial trade winds and Walker circulation show no systematic changes.

[34] The model's response to obliquity forcing is consistent with tropical marine proxy data and reconciles proxy records that were seemingly at odds with each other. Last, the model results support the hypothesis that Earth's obliquity influences ice age climate primarily through its control on meridional insolation gradients [e.g., Raymo and Nisancioglu, 2003].

[35] Acknowledgments. We greatly appreciate discussions with D. Lea and Z. Liu and their clarifications of the paleorecords and thank M. Raymo, L. Sloan, and an anonymous reviewer for their constructive comments. This work was supported by National Science Foundation grant ATM-0432503.

\section{References}

Be, A. W. H. (1977), An ecological, zoogeographic and taxonomic review of recent planktonic foraminifera, in Oceanic Micropalaeontology, edited by A. T. S. Ramsay, pp. 1-100, Elsevier, New York.

Beaufort, L., T. de Garidel-Thoron, A. C. Mix, and N. G. Pisias (2001), ENSO-like forcing on oceanic primary production during the late Pleistocene, Science, 293, 2440-2444.

Beck, J. W., J. Recy, F. Taylor, R. L. Edwards, and G. Cabloh (1997), Abrupt changes in early Holocene sea surface temperature derived from coral records, Nature, 385, 705-707.

Berger, A. L. (1978), Long term variations of daily insolation and Quaternary climate change, J. Atmos. Sci., 35, 2362-2367.

Bocaletti, G., R. C. Pakanowski, S. G. H. Philander, and A. V. Fedorov (2004), The thermal structure of the upper ocean, J. Phys. Oceanogr., 34, 888-902.

Budziak, D., R. R. Schneider, F. Rostek, P. Müller, E. Bard, and G. Wefer (2000), Late Quaternary insolation forcing on total organic carbon and $\mathrm{C}_{37}$ variations in the Arabian Sea, Paleoceanography, 15, 307-321.

Cane, M. A. (1998), Climate change-A role for the tropical Pacific, Science, 282, 56-61.

Clemens, S., W. Prell, D. Murray, G. Shimmield, and G. Weedon (1991), Forcing mechanisms of the Indian Ocean monsoon, Nature, 353, $720-725$.

Clement, A. C., R. Seager, and M. A. Cane (2000), Suppression of El Niño during the mid-Holocene by changes in the Earth's orbit, Paleoceanography, 15, 731-741.

Conte, M. H., J. K. Volkman, and G. Eglinton (1994), Lipid biomarkers of the Haptophyta, in The Haptophyte Algae, pp. 351-377, Clarendon, Oxford, U. K.

de Garidel-Thoron, T., Y. Rosenthal, F. Bassinot, and L. Beaufort (2005), Stable sea surface tem- peratures in the western Pacific warm pool over the past 1.75 million years, Nature, 433 , 294-298.

Harper, S. (2000), Thermocline ventilation and pathways of tropical-subtropical water mass exchange, Tellus, Ser. A, 52, 330-345.

Harrison, S. P., J. E. Kutzbach, Z. Liu, P. J. Bartlein, B. Otto-Bliesner, D. Muhs, I. C Prentice, and R. S. Thompson (2003), MidHolocene climate of the Americas: A dynamical response to changed seasonality, Clim. Dyn., 20, 663-688.

Jackson, C. S., and A. J. Broccoli (2003), Orbital forcing of Arctic climate: Mechanisms of climate response and implications for continental glaciation, Clim. Dyn., 21, 539-557.

Jacob, R. (1997), Low frequency variability in a simulated atmosphere ocean system, Ph.D. thesis, 159 pp., Univ. of Wis.-Madison, Madison.

Kiehl, J. T., J. J. Hack, G. B. Bonan, B. A Boville, B. P. Briegleb, D. L. Williamson, and P. J. Rasch (1996), Description of the NCAR Community Climate Model (CCM3), NCAR Tech. Note NCAR/TN-420+STR, 152 pp., Natl. Cent. for Atmos. Res., Boulder, Colo.

Lea, D. W. (2004), The 100,000-yr cycle in tropical SST, greenhouse forcing, and climate sensitivity, J. Clim., 17, 2170-2179.

Lea, D. W., D. K. Pak, and H. J. Spero (2000), Climate impact of late Quaternary equatorial Pacific sea surface temperature variations, Science, 289, 1719-1724.

Liu, Z., and T. D. Herbert (2004), High-latitude influence on the eastern equatorial Pacific climate in the early Pleistocene epoch, Nature, 427, 720-723.

Liu, Z., J. E. Kutzbach, and L. Wu (2000a), Modeling climate shift of El Niño variability in the Holocene, Geophys. Res. Lett., 27, $2265-2268$.
Liu, Z., S. Shin, P. Behling, W. Prell, M. TrendStaid, S. P. Harrison, and J. E. Kutzbach (2000b), Dynamical and observational constraints on tropical Pacific sea surface temperature at the Last Glacial Maximum, Geophys. Res. Lett., 27, 105-108.

Liu, Z., L. Wu, R. Gallimore, and R. Jacob (2002), Search for the origins of Pacific decadal climate variability, Geophys. Res. Lett., 29(10), 1404, doi:10.1029/2001GL013735.

Liu, Z., E. Brady, and J. Lynch-Stieglitz (2003), Global ocean response to orbital forcing in the Holocene, Paleoceanography, 18(2), 1041, doi:10.1029/2002PA000819.

Martinez, I., L. Keigwin, T. T. Barrows, Y. Yokoyama, and J. Southon (2003), La Niña- like conditions in the eastern equatorial Pacific and a stronger Choco jet in the northern Andes during the last glaciation, $\mathrm{Pa}$ leoceanography, 18(2), 1033, doi:10.1029/ 2002PA000877.

Merilees, P. E. (Ed.) (2003), Community Climate System Model science plan 20042008, report, Natl. Cent. for Atmos. Res., Univ. Corp. for Atmos. Res., Boulder, Colo.

Milankovitch, M. (1941), Canon of Insolation and the Ice-Age Problem, translated from German, Isr. Program for Sci. Transl., Jerusalem.

Mix, A. C., A. E. Morey, N. G. Pisias, and S. W. Hostetler (1999), Foraminiferal faunal estimates of paleotemperature: Circumventing the no-analog problem yields cool ice age tropics, Paleoceanography, 14, 350-359.

Nisancioglu, K. (2004), Modeling the impact of atmospheric moisture transport on global ice volume, Ph.D. dissertation, Mass. Inst. of Technol., Cambridge.

Okada, H., and S. Honjo (1973), The distribution of oceanic coccolithophorides in the Pacific, Deep Sea Res. Oceanogr. Abstr., 20, 355-374. 
Okada, H., and A. McIntyre (1979), Seasonal distribution of modern coccolithophorides in the western North Atlantic Ocean, Biol. Morya Vladivostok, 54, 319-328.

Peltier, W. R. (1994), Ice age paleotopography, Science, 265, 195-201.

Perks, H. M., and R. F. Keeling (1998), A 400 kyr record of combustion oxygen demand in the western equatorial Pacific: Evidence for a precessionally forced climate response, Paleoceanography, 13, 63-69.

Perks, H., C. D. Charles, and R. F. Keeling (2002), Precessionally forced productivity variations across the equatorial Pacific, Paleoceanography, 17(3), 1037, doi:10.1029/2000PA000603.

Petit, J. R., et al. (1999), Climate and atmospheric history of the past 420,000 years from the Vostok ice core, Antarctica, Nature, 399, 429-436.

Philander, S. G., and A. V. Federov (2003), Role of tropics in changing the response to Milankovitch forcing some three million years ago, Paleoceanography, 18(2), 1045, doi:10.1029/ 2002PA000837.

Pierrehumbert, R. (2004), High levels of atmospheric carbon dioxide necessary for the termination of global glaciation, Nature, 429, 646-649.

Pisias, N. G., and A. C. Mix (1997), Spatial and temporal oceanographic variability of the eastern equatorial Pacific during the late Pleisto- cene: Evidence from radiolaria microfossils, Paleoceanography, 12, 381-393.

Poulsen, C. J., R. T. Pierrehumbert, and R. L. Jacob (2001), Impact of ocean dynamics on the simulation of the Neoproterozoic "snowball Earth," Geophys. Res. Lett., 28, 1575 1578.

Poulsen, C. J., A. S. Gendaszek, and R. Jacob (2003), Did the rifting of the Atlantic Ocean cause the Cretaceous thermal maximum?, Geology, 31, 115-118.

Ravelo, A. C., D. H. Andreasen, M. Lyle, A. O. Lyle, and M. W. Wara (2004), Regional climate shifts caused by gradual global cooling in the Pliocene epoch, Nature, 429, 263-267.

Raymo, M. E., and K. Nisancioglu (2003), The

41 kyr world: Milankovitch's other unsolved mystery, Paleoceanography, 18(1), 1011 doi:10.1029/2002PA000791.

Reichart, G. J., L. J. Lourens, and W. J. Zachariasse (1998), Temporal variability in the northern Arabian Sea oxygen minimum zone (OMZ) during the last 225,000 years, Paleoceanography, 13, 607-621.

Ruddiman, W. F. (2003), Orbital insolation, ice volume, and greenhouse gases, Quat. Sci. Rev., 22, $1597-1629$.

Sarmiento, J. L., N. Gruber, M. A. Brzezinski, and J. P. Dunne (2003), High-latitude controls of thermocline nutrients and low latitude biological productivity, Nature, 427, 56-60.

Stommel, H. (1979), Determination of water mass properties of water pumped down from the Ekman layer to the geostrophic flow below, Proc. Natl. Acad. Sci. U. S. A., 76, 30513055 .

Ternois, Y., M. A. Sicre, A. Boireau, M. H. Conte, and G. Eglinton (1997), Evaluation of long-chain alkenones as paleo-temperature indicators in the Mediterranean Sea, Deep Sea Res., Part I, 44, 271-286.

Toggweiler, J. R., K. Dixon, and W. S. Broecker (1991), The Peru upwelling and the ventilation of the South Pacific thermocline, J. Geophys. Res., 96, 20,467-20,497.

Young, M. A., and R. S. Bradley (1984), Insolation gradients and the paleoclimatic record, in Milankovitch and Climate, part 2, edited by A. L. Berger et al., pp. 707-713, Springer, New York.

S.-Y. Lee and C. J. Poulsen, Department of Geological Sciences, University of Michigan, Ann Arbor, MI 48109, USA. (shihyu@umich. edu) 